\title{
Wide-body Aircraft Trip Direct Operating Cost Model Based on Trans-log Function
}

\author{
Sun Hong ${ }^{1, \mathrm{a}}$, Huang Ganxiang ${ }^{1, \mathrm{~b}, *}$, Zhou Jiesong ${ }^{1, \mathrm{c}}$, Wang $\mathrm{Yu}^{1, \mathrm{~d}}$ \\ ${ }^{1}$ College of Airport Engineering and Transportation Management, Civil Aviation Flight University of China, Guanghan, \\ Sichuan, 618307, China \\ ahanksun@263.net, ${ }^{\mathrm{b}}$ hgx312@139.com, ${ }^{\mathrm{c}} \mathrm{zj}$ s911028@163.com, ${ }^{\mathrm{d}}$ wangyu2001.111@163.com \\ *Corresponding Author
}

\begin{abstract}
In order to better instruction airlines to analysis of the civil aircraft economy, this paper proposal an widebody aircraft trip direct operating cost model from the perspective of macroscopic based on statistical analysis of airlines fleet operation cost data. Firstly, the correlation analysis be used to determine the cost model variables. Secondly, building the aircraft trip direct operation cost model based on trans-log production function, and the ordinary least squares method is used to estimate the function's coefficients. Finally, the model test using 9 aircraft direct operating cost data from 2014 indicate that the average relative error is $\mathbf{0 . 0 7 1 1}$, and an numerical example show that the cost model can be apply to route capacity allocation. So, the model is practical and feasible.
\end{abstract}

Keywords- Air Transport; Direct Operating Cost; Aircraft; Fuel Price; Trans-log.

\section{INTRODUCTION}

The economic analysis of civil aircraft is very critical to airlines, because it provides some important references for airlines to fleet planning, aircraft-route matching. While aircraft operation cost evaluation is one of the core content of economic analysis of civil aircraft, so, it is necessary to building an function of civil aircraft operating costs. Analyzing Transportation cost functions has been a subject of discussion for the past 150 years and a good survey of the more recent academic research can be found in Oum and Waters[1]. Douglas and Laurits formulated a general model of airline costs, which estimated by using panel data on large and small airlines, and result indicate that the primary factor explaining cost differences is density of traffic within an airline's network, also of major importance is the average length of individual flights[2]. Wei and Hansen develop an Econometric cost function for aircraft cost based on a de-mean trans-log model, and find that economies of aircraft size and stage length exist at the sample mean of their data set[3]. Hsien and Lopin illustrates how to calculate accurate costs, including the operating costs for individual airplanes and flights, as well as the costs per available seat kilometers, and per available ton kilometers using activity based costing[4]. Ryerson and Hansen examine the impact of fuel price on aircraft costs and airline operational strategies by developing two classes of operating cost models for jet aircraft and comparing the results, and points that fuel consumption reduction largely coming from upgauging and new and advanced technologies[5]. Swan and Adler disaggregates aircraft operating costs into various cost categories and provides background for an engineering approach used to compute a generalized single-aisle and twin-aisle aircraft trip cost function[6]. Ssamula and Mistro use an operating cost model to analyse suitable choices, in terms of costrelated parameters, of aircraft commonly used for shorthaul routes within Africa[7]. WANG use the NASA 97 method to generate samples of direct operating cost for various aircraft types over any mix of flying distance, building the calculation model of direct operation cost for aircraft-type-rank based on seat class and designed range of the corresponding airplanes[8]. But it fails to consider the strong linear correlation between seat class and designed range of the corresponding airplanes, and the sample data is not the airline actual operating cost data, so the model can not comprehensively reflect the actual operating situation.

Therefore, based on the above study, this paper uses the airline actual operating cost data as samples, introduces trans-log production function into statistical analysis of cost function, and builds the wide-body aircraft trip direct operating cost model from the macroscopic level. The following sections are organized as follows: 1) Section 2 will illustrate the data sources and processing. 2) Section 3 will determine the model variables. 3) Section 4 will construct wide-body aircraft trip direct operating model. 4 ) Section 5 will give an example of cost model application to routes capacity allocation. 5) Section 6 will conclude the entire paper.

\section{DATA SOURCES AND PROCESSING}

In this research, we use the data from the US Department of Transportation Form 41. In Form 41, the total airline costs are classified into two main function groups: direct operating cost, which includes aircraft operating expenses; and indirect operating cost, which includes all other expenses. Aircraft operating cost categories include flying operation cost (such as salary and benefits for pilots and other flight personnel except flight attendants, aircraft oil, fuel, and aircraft rental cost); flight equipment maintenance; flight equipment depreciation and amortization; expense of interchange aircraft. Data for these expense items are available by airline and aircraft type for each quarter. In this study, we focus on the building long-haul aircraft trip cost model, and hence only use the wide-body aircraft cost data in modeling. 
Downloading the long-haul aircraft cost data from the first quarter of 2008 until the fourth quarter of 2013, include American Airlines (AA), Delta Airlines (DL), United Airlines (UA), US Airways (US), Northwest Airlines (NW), Continental Airlines (CO), Hawaiian Airlines (HA), North American Airlines (NA), World Airways (WO) and Omni Air Express (X9), total is 24 quarters and the data processing programs are as follows:

1) Screening wide-body aircraft operating cost data, Removing the abnormal data, and calculating the average stage length (traveled per departure kilometres), block hours (block hours per departure), aircraft trip direct operating cost (direct operating cost per departure) and fuel price (ratio of the amount spent on fuel to the amount consumed \$/gallon).

2) In order to eliminate the effects of inflation, converting operation costs and fuel prices for each year of data into constant dollars of 2008 years by using the consumer price index.

After the above processing, 1486 trips direct operating cost data include 13 aircraft models are obtained, which aircraft types are shown Table 1. A descriptive statistics is shown in Table 2, and using these data to conduct a statistical analysis of the trip direct operating cost model.

\section{MODEL VARIABLES DETERMINED}

This paper researches the wide-body aircraft trip direct operating cost from the perspective of the average statistical and doesn't consider the airlines operation difference, meteorological environment, flight altitude, cruise speed and other factors, which have effect on aircraft trip direct operating cost (DOC). It just considering the following six factors[9]: average stage length (ASL), block hours (Bhours), maximum takeoff weight (MTOW), seat capacity (Seat), design range (Range) and fuel price (Fprice). In addition, considering variation in long-haul configurations among airlines and across regions, the typical three-class configuration for various aircraft models are presented in Table 1.

Analysis of the correlation between the six variables to aircraft trip direct operating cost. The result shown in Table 3 indicates that the correlation coefficient of average stage length and block hours is reached 0.99, the correlation coefficient between maximum takeoff weight and seat capacity and design range are 0.98 and 0.71 respectively. Therefore, according to the size of the correlation coefficients and the correlation among variables, the average stage length, maximum takeoff weight and fuel price should be selected as the trip cost model explanatory variables.

\section{AIRCRAFT TRIP DIRECT OPERATING MODEL}

The production function model was first proposed by the American economist P.Douglas and C.Cobb based on the industrial statistical data of 1899-1922. The model is different from the traditional mathematical method when established the object input and output relationship, and it be good at describing nonlinear. Trans-log production function is a generalization of the Cobb-Douglas production function, it is an flexible production function model with easy estimate and strong tolerance, and it belongs to the Quadratic Response Surfaces functional in structure[10] and has been widely used in cost estimation studies for airlines as well as other transport industries.

So, based on trans-log production function which can be used logarithmic transformation translate into linear function, building the wide-body aircraft trip direct operating cost function as following:

$$
\begin{aligned}
\ln D O C= & a_{1} \ln W+a_{2} \ln D+a_{3} \ln F+a_{4} \ln ^{2} W+a_{5} \ln ^{2} D+a_{6} \ln ^{2} F+ \\
& a_{7} \ln W \ln D+a_{8} \ln W \ln F+a_{9} \ln D \ln F+
\end{aligned}
$$

Where: DOC represent the trip aircraft direct operating cost; $\mathrm{W}$ is the maximum takeoff weight; $\mathrm{D}$ is the average stage length; $F$ is the fuel price; is coefficients to be estimated.

The ordinary least squares method is used to estimating the Eq. 1 coefficients, and the regression analysis result show that the goodness of fit reaches 0.8534 , and most of the variables are statistically significant at the $95 \%$ confidence level. The specific parameter estimation result is shown in Table 4.

Furthermore, the model accuracy tests by using 9 aircraft trip direct operating cost data from 2014 years, and the result presented in table 5 showing that the average relative error is 0.0711 , So, the model is practical and feasible. But, it is a remarkable fact that the model estimating the aircraft types of B788 and B777-300ER trip cost more highly than actual cost compared with other aircrafts shown in Table 5, due to these aircraft designing and manufacturing time later, and with more technical and fuel economy.

\section{MODEL APPLICATION}

In this Section, we will simulation of an airline's international route network and used the cost model to airline fleet planning by construct the following routes capacity allocation model:

$$
\min Z=\sum_{i=1}^{n} \sum_{j}^{m} x_{i j} c_{i j}
$$

Subject to:

$$
\begin{aligned}
& \sum_{i=1}^{n} x_{i j} s_{i} l_{i j} \geq d_{j} \quad \forall j \in J \\
& \sum_{i=1}^{n} x_{i j} \geq f_{j} \quad \forall j \in J \\
& \sum_{i=1}^{n} x_{i j} \leq F_{j} \quad \forall j \in J \\
& \sum_{i=1}^{n} y_{i} \leq p
\end{aligned}
$$

Where $x_{i j}$ represents the aircraft type $i$ flight frequencies on route $j$ (uniderection). $c_{i j}$ is the per departure direct operating cost of aircraft types $i$ flight on route $j$. $d_{j}, f_{j}, F_{j}$ and $p$ denote the airlines can achieved the passenger demand on routes $j$, airline require minimum frequencies and can obtained the maximum frequencies on route $j$, and the maximum aircraft types numbers airlines can be afford, respectively. $s_{i}$ is the seat numbers of aircraft types $i ; l_{i j}$ is the average load factors about aircraft types $i$ flight on route $j ; y_{i}$ is the indicator variables, if the aircraft types $i$ have been selected by the airline, $y_{i}=1$ otherwise $y_{i}=0$. Notice that the objective function (2) minimizes the total direct operating the airline. 
Constraints (3) are the demand constraints, for each routes, the available seat capacity mustn't less than the passenger demand. Constraints (4) and Constraints (5) are the frequencies capacity constraints, for each routes, the available frequencies mustn't less than the airline require minimum frequencies and mustn't more than exceed the maximum frequencies airline can be obtained, respectively. Constraints (6) is the aircraft types numbers constraints, for each aircraft types $i$, the total selected aircraft types mustn't exceed the maximum aircraft types numbers airlines can be afford.

The airlines operating international routes data are shown in Table 6, and we assumed the fuel price is 2.0 $\$$ /gallon, all route average load factor are $80 \%$, and airline can operating the maximum aircraft types numbers is 3 .

The available alternative aircraft types are shown in Table 7.

This computational experiment is realized by Lingo 8.0 under computer configuration with $2 \mathrm{G}$ memory and $2.40 \mathrm{GHz} \mathrm{CPU}$ frequency, and routes capacity allocation result are shown in Table 8 . The result indicate that the type 1 , type 3 , and type 5 aircraft is the airline appropriate international route aircraft.

TABLE 1 VARIOUS WIDE-BODY AIRCRAFT PARAMETERS

\begin{tabular}{|l|c|c|c|}
\hline Aircraft types & MTOW/ tons & $\begin{array}{c}\text { Typical three- } \\
\text { class }\end{array}$ & $\begin{array}{c}\text { Design } \\
\text { range/ } \\
\text { kilometres }\end{array}$ \\
\hline A330-300 & 242 & 295 & 11300 \\
\hline A300-600 & 172 & 220 & 7540 \\
\hline A330-200 & 242 & 253 & 13400 \\
\hline B787 & 228 & 228 & 14500 \\
\hline B747-200 & 378 & 366 & 12690 \\
\hline B747-400 & 397 & 412 & 13450 \\
\hline B767-200ER & 179 & 181 & 11825 \\
\hline B767-300ER & 187 & 218 & 11090 \\
\hline B767-400ER & 204 & 245 & 10418 \\
\hline B777-200ER & 298 & 314 & 14310 \\
\hline B777-300ER & 352 & 386 & 14490 \\
\hline DC-10-30 & 259 & 255 & 10622 \\
\hline MD-11 & 273 & 293 & 12670 \\
\hline
\end{tabular}

TABLE 2 DESCRIPTIVE STATISTICS OF THE SAMPLE DATA

\begin{tabular}{|c|c|c|c|c|c|}
\hline Variable & $\begin{array}{c}\text { Samples } \\
\text { Capacity }\end{array}$ & Mean & $\begin{array}{c}\text { Std. } \\
\text { Dev }\end{array}$ & Minimum & Maximum \\
\hline $\begin{array}{c}\text { Stage } \\
\text { length }\end{array}$ & 1486 & 5576 & 2496 & 300 & 12901 \\
\hline $\begin{array}{c}\text { block } \\
\text { hours }\end{array}$ & 1486 & 7.3 & 2.8 & 1.3 & 16.0 \\
\hline Seat & 1486 & 260 & 56 & 166 & 430 \\
\hline $\begin{array}{c}\text { Fuel } \\
\text { prices }\end{array}$ & 1486 & 2.6 & 0.6 & 0.6 & 4.8 \\
\hline
\end{tabular}

TABLE 3 CORRELATION COEFFICIENT MATRIX

\begin{tabular}{|c|c|c|c|c|c|c|c|}
\hline & DOC & ASL & Bhours & MTOW & Seat & Range & Fprice \\
\hline DOC & 1.00 & 0.65 & 0.64 & 0.49 & 0.47 & 0.31 & 0.30 \\
\hline ASL & 0.65 & 1.00 & 1.00 & 0.26 & 0.28 & 0.27 & 0.11 \\
\hline Bhours & 0.64 & 1.00 & 1.00 & 0.23 & 0.25 & 0.24 & 0.12 \\
\hline MTOW & 0.49 & 0.26 & 0.23 & 1.00 & 0.98 & 0.71 & 0.02 \\
\hline Seat & 0.47 & 0.28 & 0.25 & 0.98 & 1.00 & 0.62 & 0.03 \\
\hline Range & 0.31 & 0.27 & 0.24 & 0.71 & 0.62 & 1.00 & 0.01 \\
\hline Fprice & 0.30 & 0.11 & 0.12 & 0.02 & 0.03 & 0.01 & 1.00 \\
\hline
\end{tabular}

TABLE 8 AIRCRAFT TYPES FLIGHT FREQUENCIES ON ROUTES

\begin{tabular}{|c|c|c|c|c|c|}
\hline Routes & Type1 & Type2 & Type3 & Type4 & Type5 \\
\hline 1 & 0 & 0 & 271 & 0 & 0 \\
\hline 2 & 0 & 0 & 74 & 0 & 26 \\
\hline 3 & 0 & 0 & 33 & 0 & 67 \\
\hline 4 & 55 & 0 & 0 & 0 & 45 \\
\hline 5 & 0 & 0 & 1227 & 0 & 0 \\
\hline
\end{tabular}

TABLE 4 REgRESSION ANALYSIS RESULTS FOR AIRCRAFT DIRECT OPERATING COST FUNCTION BASED ON TRANS-LOG MODEL

\begin{tabular}{|c|c|c|c|c|}
\hline Variable & Coefficient & Std. Error & t-Statistic & Prob. \\
\hline$a_{1}$ & -3.3748 & 1.1027 & -3.0604 & 0.0023 \\
\hline$a_{2}$ & 1.3186 & 0.3247 & 4.0613 & 0.0001 \\
\hline$a_{3}$ & -1.5193 & 0.5480 & -2.7725 & 0.0056 \\
\hline$a_{4}$ & 0.3979 & 0.1005 & 3.9610 & 0.0001 \\
\hline$a_{5}$ & -0.0077 & 0.0169 & -0.4534 & 0.6503 \\
\hline$a_{6}$ & 0.1858 & 0.0430 & 4.3176 & 0.0000 \\
\hline$a_{7}$ & -0.0707 & 0.0446 & -1.5842 & 0.1134 \\
\hline$a_{8}$ & 0.3263 & 0.0864 & 3.7770 & 0.0002 \\
\hline$a_{9}$ & -0.0031 & 0.0392 & -0.0785 & 0.9374 \\
\hline$a_{10}$ & 9.6938 & 3.4996 & 2.7700 & 0.0057 \\
\hline
\end{tabular}

TABle 5 DEVIATION TEST TABLE

\begin{tabular}{|c|c|c|c|c|c|}
\hline Airplane & $\begin{array}{c}\text { Stage } \\
\text { length }\end{array}$ & $\begin{array}{c}\text { Fuel } \\
\text { price }\end{array}$ & $\begin{array}{c}\text { Actual } \\
\text { trip cost }\end{array}$ & $\begin{array}{c}\text { Estimated } \\
\text { trip cost }\end{array}$ & $\begin{array}{c}\text { relative } \\
\text { error }\end{array}$ \\
\hline $\begin{array}{c}\text { A330- } \\
300\end{array}$ & 6685 & 2.79 & 68795 & 73329 & $6.59 \%$ \\
\hline $\begin{array}{c}\text { A330- } \\
200\end{array}$ & 5554 & 2.64 & 57963 & 61256 & $5.68 \%$ \\
\hline $\begin{array}{c}\text { B787- } \\
800\end{array}$ & 7490 & 2.66 & 65414 & 77941 & $19.15 \%$ \\
\hline $\begin{array}{c}\text { B747- } \\
400\end{array}$ & 8220 & 2.72 & 136973 & 131221 & $4.20 \%$ \\
\hline $\begin{array}{c}\text { B767- } \\
200 \mathrm{ER}\end{array}$ & 4186 & 2.37 & 39151 & 38709 & $1.13 \%$ \\
\hline $\begin{array}{c}\text { B767- } \\
300 \mathrm{ER}\end{array}$ & 5238 & 2.68 & 50180 & 50359 & $0.36 \%$ \\
\hline $\begin{array}{c}\text { B767- } \\
400 \mathrm{ER}\end{array}$ & 6428 & 2.73 & 62112 & 63010 & $1.44 \%$ \\
\hline $\begin{array}{c}\text { B777- } \\
200 \mathrm{ER}\end{array}$ & 7734 & 2.67 & 96753 & 93738 & $3.12 \%$ \\
\hline $\begin{array}{c}\text { B777- } \\
300 \mathrm{ER}\end{array}$ & 7385 & 2.57 & 87761 & 102366 & $16.64 \%$ \\
\hline
\end{tabular}

TABLE 6 AIRLINES ROUTES DATA

TABLE 7 AVAILABLE ALTERNATIVE AIRCRAFT TYPES

\begin{tabular}{|c|c|c|c|c|c|}
\hline Aircraft & Type1 & Type2 & Type3 & Type4 & Type5 \\
\hline MTOW & 204 & 396 & 299 & 575 & 242 \\
\hline Seats & 228 & 412 & 386 & 555 & 295 \\
\hline
\end{tabular}

\begin{tabular}{|c|c|c|c|c|}
\hline Routes & Distance & $\begin{array}{c}\text { Yearly } \\
\text { passenger }\end{array}$ & $\begin{array}{c}\text { Min year } \\
\text { frequencies }\end{array}$ & $\begin{array}{c}\text { Max year } \\
\text { frequencies }\end{array}$ \\
\hline 1 & 11880 & 83377 & 100 & 1500 \\
\hline 2 & 3520 & 28862 & 100 & 1500 \\
\hline 3 & 11055 & 25996 & 100 & 1500 \\
\hline 4 & 3406 & 20629 & 100 & 1500 \\
\hline 5 & 11145 & 378841 & 100 & 1500 \\
\hline
\end{tabular}




\section{CONCLUSION}

In this paper we used the airlines actual operation cost data to construct a wide-body aircraft trip direct operation cost from the macroscopic, and the model test show that the average relative error is 0.0711 , and an numerical example show that the cost model can be apply to route capacity allocation, which verifies the feasibility of the proposed model. The cost model can providing some important references for airlines to fleet planning, aircraftroute matching. In addition, the model can better analyze the impact of fuel price fluctuations on the airline fleet composition, due to the fuel price variable has been introduced into the model. It should be pointed out that this paper didn't consider other cost factors such as the price of labour, engine performance, flight altitude, cruising speed and so on. Along with the science and technology progress, especially the application of advanced engine technology, new composite materials and new aircraft design and manufacturing process technology, the aircraft unit operation cost will continue to reduced and the parameters of the model will be changed. So this model applies only to the current industrial technology level.

\section{ACKNOWLEDGMENT}

This work was financially supported by the National Science Foundation of China (61179074) and Civil Aviation Science and Technology of China (MHRD20130303).

\section{REFERENCES}

[1] Oum, T. H. , Waters W.G. A survey of recent developments in transportation cost function research. Logistics and Transportation Review,1996,32(4):423-463.

[2] Douglas W. Caves, Laurits R. Christensen, Michael W. Tretheway. Economies of density versus economies of scale: why trunk and local service airline costs differ[J].Rand Journal of Economics, 1984,15(4):471-489.

[3] Wenbin Wei, Mark Hansen. Cost Economic of Aircraft Size[J].Journal of Transport Economic and Policy,2003,37(2):279296.

[4] Wen-Hsien Tsai, Lopin Kuo. Operating costs and capacity in the airline industry[J]. Journal of Air Transport Management,2004,10:271-277.

[5] Megan Smirti Ryerson, Mark Hansen. Capturing the impact of fuel price on jet aircraft operating costs with Leontief technology and econometric models[J].Transportation Research Part C,2013,33:282-296

[6] William M. Swan, Nicole Adler. Aircraft trip cost parameters: A function of stage length and seat capacity $[\mathrm{J}]$. Transportation Research Part E,2006,42:105-115.

[7] B Ssamula, R Del Mistro and A T Visser. Using an operating cost model to analyse the selection of aircraft type on short-haul routes[J]. JOURNAL OF THE SOUTH AFRICAN INSTITUTION OF CIVIL ENGINEERING,2006,48(2):2-9.

[8] Y. Wang, H. Sun, X. D. Wang et al. Civil Passenger Aircraft DOC Calculating Model Based on Constructed Virtual Aircraft-TypeRank $[J]$. Journal of Transportation Systems Engineering and Information Technology, 2013,13(4):120-125. (In Chinese)

[9] Y. P. Ye. Civil Aircraft Economy[M].Chengdu: Southwest Jiaotong University Press, 2013. (In Chinese)

[10] L. R. Wu, F. F. Liang, Z. K. Shi. China's Trans-log Production Function Model of Losses of Traffic Accidents[J].MATHEMATICS IN PRACTICE AND THEORY 2010,40(22):56-60. (In Chinese) 